\title{
Milk Temperature Influences Esophageal Motility In The Newborn
}

\section{Lamb}

\author{
Djamal Djeddi, Nathalie Samson, Jean-Paul Praud
}

Neonatal Respiratory Research Unit, Department of Pediatrics and Physiology, Université de Sherbrooke, QC, Canada, J1H 5N4

Short title: Milk temperature and esophageal motility in newborn lambs

\section{Address for correspondence and proofs:}

Djamal-Dine Djeddi, MD PhD

Departments of Pediatrics and Physiology

Université de Sherbrooke

J1H 5N4, QC Canada

Tel: (819) 346-1110, ext 14872

Fax: (819) 564-5215

email: Djamal-Dine.Djeddi@Usherbrooke.ca

Conflicts of Interest: The authors disclose no conflicts.

Acknowledgements and Source of Funding: The authors gratefully acknowledge the MMS Company (Enschede, Holland) for the gracious lending of the MII-pH monitoring equipment. Djamal Djeddi was supported by the Department of Pediatrics, Amiens University Hospital, France. The study was also supported by the Canada Research Chair in Neonatal Respiratory Physiology allocated to Jean-Paul Praud. Jean-Paul Praud is a member of the FRSQ-funded Clinical Research Center Étienne-Le Bel, Sherbrooke University Hospital. 


\begin{abstract}
Esophageal dysmotility is common in infants. We aimed to evaluate the influence of milk temperature on esophageal motility using multichannel impedance-pH monitoring (MII-pH). Five healthy lambs, aged 2-3 days, underwent a MII-pH while bottle-fed randomly with $50 \mathrm{ml}$ of ewe milk at $26^{\circ}, 38.5^{\circ}$ and $41.5^{\circ} \mathrm{C}$. Impedance motility parameters were studied on 5 swallows at each temperature. At $38.5^{\circ} \mathrm{C}$ we noted a higher total propagation velocity and a shorter total bolus transit time $(p<0.05)$. Those unique results suggest a potential role for milk temperature alterations to improve oral feeding in infants with esophageal dysmotility.
\end{abstract}

Keywords: swallowing; animal model; multichannel impedance monitoring

\title{
Main text
}

The primary function of the esophagus is to transport swallowed material from the pharynx to the stomach. Numerous treatments have been proposed to improve swallowing disorders, such as modification of the ingesta volume, composition or viscosity $[1,2]$. To our knowledge, however, no study has explored the impact of milk temperature on newborn esophageal motility.

Previous in vivo studies have demonstrated similarities between the ovine and human esophagus with respect to thickness and histological structure [3]. This led us to hypothesize that the newborn lamb is a relevant model for swallowing studies in certain neonatal conditions.

Our aim was thus to determine esophageal motility characteristics in different milk temperature conditions in the healthy, newborn lamb at term, using for the first time MII-pH in a newborn animal. The application would be to adapt the diet to the needs of dysphagic infants.

MII-pH was performed in 5 lambs aged from 2 to 3 days and weighing $3.6 \pm 0.7 \mathrm{Kg}$ on the experimental day. All lambs were born at term by spontaneous vaginal delivery and were bottle fed with reconstitute ewe milk (please refer to the Supplementary material file for additional information). 
The study was approved by the ethics committee for animal care and experimentation of the Université de Sherbrooke, Québec.

Lambs were studied while comfortably positioned in a sling. They were given a $50 \mathrm{ml}$ bottle of reconstitute ewe milk at 3 different temperatures in a random order: $26^{\circ}, 38.5^{\circ}$ and $41.5^{\circ} \mathrm{C}$. The milk was warmed by a digital water bath that provides a reliable temperature control (Temperature uniformity: $\pm 0.2^{\circ} \mathrm{C}$ and stability: $\pm 0.25^{\circ} \mathrm{C}$ ). When the desired temperature was reached, the milk was given immediately. The suckling duration was less than $15 \mathrm{~s}$. The same custom made bottle and teat were used for all lambs. Two successive feeding episodes were separated by one hour.

Definitions of swallowing variables and characteristic pattern produced by a bolus swallow in the MII$\mathrm{pH}$ recording have been described in a previous publication [4].

Statistical analysis is detailed in the Supplementary material.

Mean lamb body temperature was $39.1^{\circ} \mathrm{C}(0.9)$. All swallows studied were complete in each temperature condition. The mean total bolus transit time was significantly shorter at $38.5^{\circ} \mathrm{C}(\mathrm{P}<0.05)$ compared to $26^{\circ} \mathrm{C}$ and $41.5^{\circ} \mathrm{C}(0.8 \mathrm{~s}$ vs $1.0 \mathrm{~s}$ and $0.8 \mathrm{~s}$ vs $1.0 \mathrm{~s})$. Moreover, the total propagation velocity was significantly higher at $38.5^{\circ} \mathrm{C}(\mathrm{P}<0.05)$ if compared with $26^{\circ} \mathrm{C}$ and $41.5^{\circ} \mathrm{C}(16$ vs $13 \mathrm{~cm} / \mathrm{s}$ and 16 vs $14 \mathrm{~cm} / \mathrm{s})$. No significant difference for both variables was seen between $26^{\circ}$ and $41.5^{\circ} \mathrm{C}$.

The other esophageal swallowing variables were not significantly changed (please refer to the Supplementary material file).

This study was performed to measure the impact of different milk temperatures (within the range used in human newborns) on esophageal motility. Very few data are available on esophageal thermoreceptors and their effect on esophageal motility. Three types of thermoreceptors have been described in cats: warm (range of discharge $\left.39-50^{\circ} \mathrm{C}\right)$, cold $\left(10-35^{\circ} \mathrm{C}\right)$ and mixed receptors $\left(10-35\right.$ and $\left.39-50^{\circ} \mathrm{C}\right)$. Warm receptor stimulation was found to depress nerve-induced contractions of the proximal esophagus, while cold receptor stimulation increased them [5]. In addition, mean esophageal transit time is transiently increased after cold 
water ingestion in humans [6]. Our results in lambs suggest that modulation of esophageal thermoreceptor activity by milk temperature can alter esophageal body motility in newborn mammals. Importance of those results stems from the well-known immaturity of esophageal body motor function in the newborn, especially preterm [7-9], as well as marked anomalies of this motor function in disorders such as diaphragmatic hernia, gastroschisis or esophageal atresia [10]. While recent data showing that the pharyngeal swallowing reflex is delayed the most around body temperature in elderly dysphagic people [11], we propose that the esophageal phase of swallowing might be improved by using milk temperature close to body temperature in neonatal conditions with immature or impaired esophageal motility.

\section{References}

1. Almeida MB, et al. J Appl Oral Sci. 2011;19(6):554-9.

2. Gravesen F, et al. World J Gastroenterol. 2011;17(15):1982-8.

3. Cavuşoğlu H, et al. J Neurosurg Spine 2009;11:547-54.

4. Di Pace MR, et al. J Pediatr Surg. 2011;46(3):443-51.

5. Christensen J. Am J Physiol. 1984;246(3 Pt 1):G221-5.

6. Jørgensen F, et al. Clin Physiol. 1994;14(1):63-9.

7. Staiano A, et al. Gastroenterology. 2007;132(5):1718-25.

8. Omari TI, et al. Gastroenterology. 1995;109(6):1757-64.

9. Gupta A, et al. Am J Gastroenterol. 2009;104(2):411-9.

10. Jadcherla SR, et al. J Pediatr Gastroenterol Nutr. 2008;47(2):158-64.

11. Ebihara S, et al. Yakugaku Zasshi. 2011;131(12):1677-81. 